NATIONAL LABORATORY

\title{
A PRELIMINARY COST STUDY OF THE DUAL MODE INVERTER CONTROLLER
}

\author{
J. W. McKeever \\ J. M. Bailey \\ S. Das
}

Oak Ridge National Laboratory

\author{
J. S. Lawler
}

The University of Tennessee-Knoxville

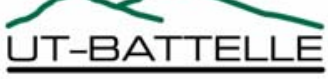


This report was prepared as an account of work sponsored by an agency of the United States Government. Neither the United States Government nor any agency thereof, nor any of their employees, makes any warranty, express or implied, or assumes any legal liability or responsibility for the accuracy, completeness, or usefulness of any information, apparatus, product, or process disclosed, or represents that its use would not infringe privately owned rights. Reference herein to any specific commercial product, process, or service by trade name, trademark, manufacturer, or otherwise, does not necessarily constitute or imply its endorsement, recommendation, or favoring by the United States Government or any agency thereof. The views and opinions of authors expressed herein do not necessarily state or reflect those of the United States Government or any agency thereof. 
Engineering Science \& Technology Division

\title{
A PRELIMINARY COST STUDY OF THE DUAL MODE INVERTER CONTROLLER
}

\author{
J. W. McKeever \\ J. M. Bailey \\ S. Das \\ J. S. Lawler
}

Publication Date: January 2005

Prepared by the

OAK RIDGE NATIONAL LABORATORY

Oak Ridge, Tennessee 37831

managed by

UT-BATTELLE, LLC

for the

U.S. DEPARTMENT OF ENERGY

Under contract DE-AC05-00OR22725 


\section{TABLE OF CONTENTS}

Page

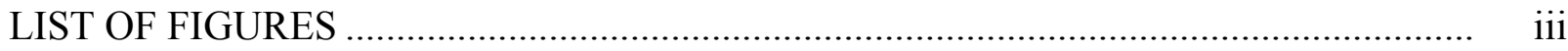

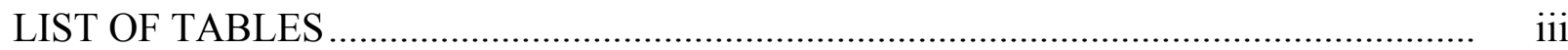

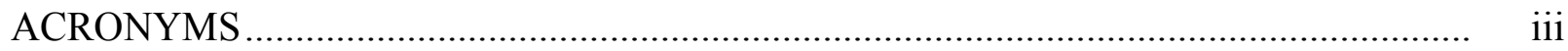

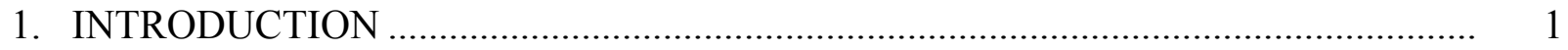

2. ROLE OF SELF-INDUCTANCE IN PERFORMANCE AND CONTROL

OF PM MOTORS ................................................................................................... 3

2.1 IMPACT OF INDUCTANCE ON THE CPSR OF THE BDCM ......................... 3

2.2 BOUNDING INDUCTANCES FOR CPA ……………………….................. 3

2.3 BOUNDING INDUCTANCES FOR DMIC ................................................... 5

2.4 BOUNDING INDUCTANCES FOR THE PMSM ……...................................... 6

3. DMIC MINIMIZES CURRENT IN PMSMs AND BDCMs ........................................ 10

4. MOTOR AND INVERTER COST STUDY ............................................................. 12

4.1 ESTIMATING LIFE CYCLE COSTS AND BENEFITS ...................................... 19

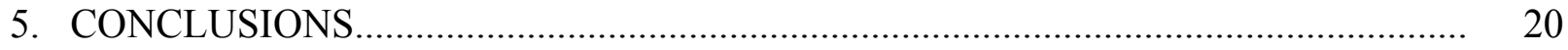

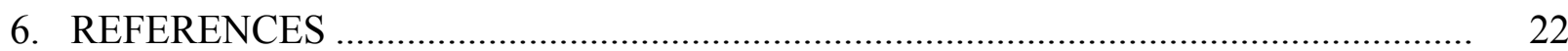

APPENDIX: SELF-INDUCTANCE AND ITS LIMITING PARAMETERS ........................ 23 


\section{LIST OF FIGURES}

Figure

1 Model of voltage fed inverter (left) and PM motor (right) configured for

Page

DMIC control (dashed box) .......................................................................... 1

2 Per-phase fundamental phasor model of trapezoidal back-emf used to analyze CPA at high speed ......................................................................... 4

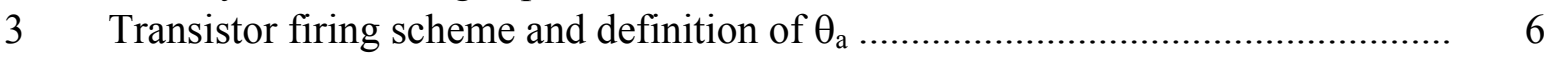

4 Per-phase phasor model of sinusoidal back-emf used to analyze CPA at high speed ....................................................................................... 7

5 Constant power operation of a PMSM comparing CPA control with DMIC ......... 11

6 Today's relative inverter component costs based on the ORNL study (10,000 units)

7 Today's relative inverter component costs based on vendor estimates

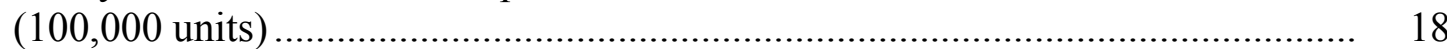

8 Relative cost goal of inverter components for a FreedomCAR subcontractor ....... 18

\section{LIST OF TABLES}

Table

Page

$1 \quad$ Motor designs investigated for motor cost study ............................................ 13

$2 \quad$ Weight of components in motor cost study ..................................................... 14

3 Cost comparison of PM motors with surface-mounted magnets .......................... 14

4 Inverter and motor currents under CPA and DMIC for selection of devices in cost study ............................................................................... 15

5 Selection of expensive inverter components based on motor design voltages and simulation currents....................................................................... 17

$6 \quad$ Inverter costs for production volume of 10,000 units ........................................ 17

\section{ACRONYMS}

\begin{tabular}{|c|c|c|c|}
\hline $\begin{array}{l}\text { BDCM } \\
\text { CPA }\end{array}$ & $\begin{array}{r}\text { brushless dc motor } \\
\text { conventional phase advance }\end{array}$ & PEEMRC & $\begin{array}{r}\text { Power Electronics and Electric } \\
\text { Machinery Research Center }\end{array}$ \\
\hline CPSR & constant power speed ratio & PM & permanent magnet \\
\hline DMIC & dual mode inverter control & PMSM & permanent magnet synchronous \\
\hline IGBT & insulated gate bipolar transistor & & motor \\
\hline IPM & interior-mounted permanent magnet & SCR & silicon-controlled rectifier \\
\hline OEM & original equipment manufacturer & SPM & surface-mounted permanent magnet \\
\hline ORNL & Oak Ridge National Laboratory & $\begin{array}{l}\text { UTK } \\
\text { VSI }\end{array}$ & $\begin{array}{l}\text { University of Tennessee-Knoxville } \\
\text { voltage source inverter }\end{array}$ \\
\hline
\end{tabular}




\section{INTRODUCTION}

In 1998, the Power Electronics and Electric Machinery Research Center (PEEMRC) at the Oak Ridge National Laboratory (ORNL) started a program to investigate alternate field weakening schemes for permanent magnet (PM) motors. The adjective "alternate" was used because at that time, outside research emphasis was on motors with interior-mounted PMs (IPMs). The PEEMRC emphasis was placed on motors with surface-mounted PMs (SPMs) because of the relative ease of manufacturing SPM motors compared with the IPM motors. Today the PEEMRC is continuing research on SPMs while examining the IPMs that have been developed by industry.

Out of this task - the goal of which was to find ways to drive PM motors that inherently have low inductance at high speeds where their back-emf exceeds the supply voltage-ORNL developed and demonstrated the dual mode inverter control (DMIC) [1,2] method of field weakening for SPM motors. The predecessor of DMIC is conventional phase advance (CPA), which was developed by UQM Technologies, Inc. [3]. Fig. 1 shows the three sets of anti-parallel thyristors in the dashed box that comprise the DMIC. If one removes the dashed box by shorting each set of anti-parallel thyristors, the configuration becomes a conventional full bridge inverter on the left driving a three phase motor on the right. CPA may be used to drive this configuration ORNL's initial analyses of CPA and DMIC were based on driving motors with trapezoidal backemfs [4-6], obtained using double layer lapped stator windings with one slot per pole per phase. A PM motor with a sinusoidal back-emf obtained with two poles per slot per phase has been analyzed under DMIC operation as a University of Tennessee-Knoxville (UTK) doctoral dissertation [7]. In the process of this research, ORNL has completed an analysis that explains and quantifies the role of inductance in these methods of control.

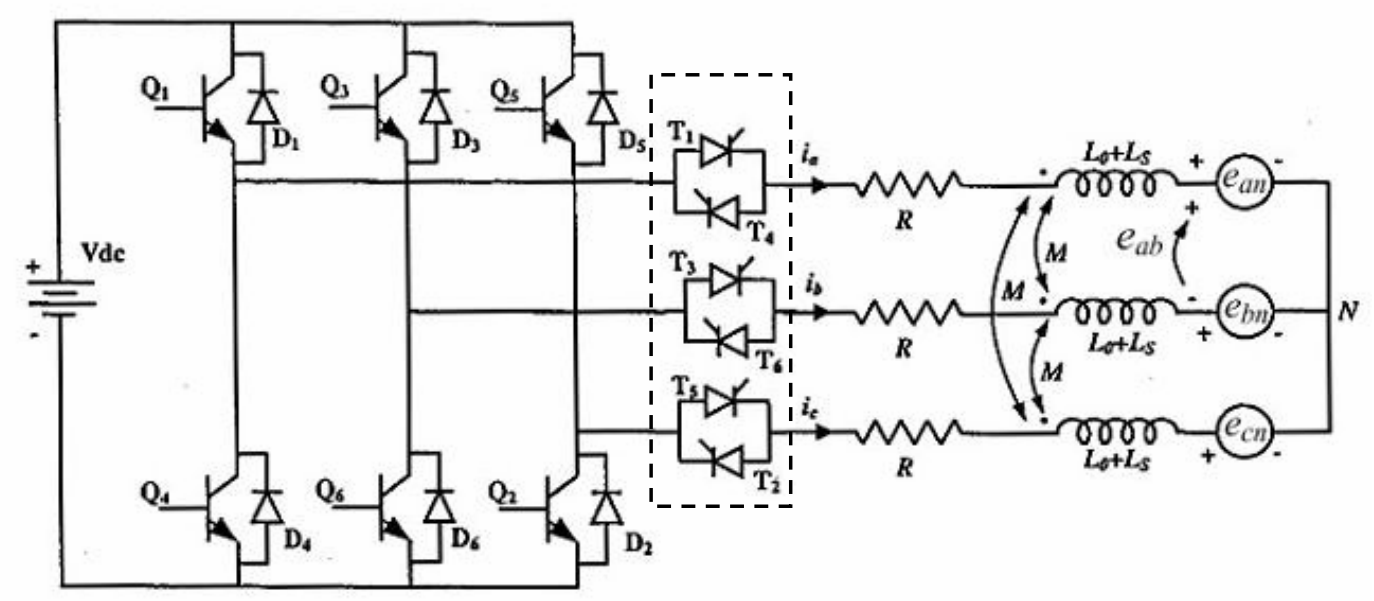

Fig. 1. Model of voltage fed inverter (left) and PM motor (right) configured for DMIC control (dashed box)

The Appendix includes information on the equations for the three components of phase inductance, $\mathrm{L}_{\text {gap }}, \mathrm{L}_{\text {slot }}$, and $\mathrm{L}_{\text {endturns. }}$ PM motors inherently have a lower inductance because of the increase in effective air gap caused by the magnet, which is in the denominator of the equation for $\mathrm{L}_{\mathrm{gap}}$. $\mathrm{L}_{\mathrm{gap}}$ accounts for about half of the phase inductance. Because of the low 
inductance, there is a propensity for currents to exceed the motor's rated value. DMIC solves this problem for low-inductance PM motors and, in addition, provides a number of safety features that protect against uncontrolled generator mode operation [8,9]; however, the DMIC topology adds a pair of anti-parallel thyristors in each of the three phases, thereby introducing additional silicon costs as well as additional voltage drops during operation. It poses the tradeoff question; under what conditions can the beneficial features of DMIC offset its additional silicon cost and voltage drop losses?

The purpose of this report is to address the tradeoff question. Sections of the report will

- review the role of self-inductance in performance and control of PM motors,

- discuss the bounding inductances for motors with trapezoidal back-emfs under CPA control,

- discuss the bounding inductances for trapezoidal back-emfs under DMIC,

- discuss the bounding inductances for the PM synchronous motor (PMSM),

- present the analysis showing how DMIC minimizes current in PMSMs,

- present the results of a cost study conducted for two motors driven using a CPA inverter and for two motors driven using DMIC,

- discuss estimating life cycle cost benefits, and

- present conclusions. 


\section{ROLE OF SELF-INDUCTANCE IN PERFORMANCE AND CONTROL OF PM MOTORS}

The armature windings of PM motors with surface-mounted magnets can be positioned to achieve a trapezoidal or a sinusoidal back-emf. A machine with a trapezoidal back-emf is called a brushless dc motor (BDCM). One with a sinusoidal-back emf is commonly referred to as a PMSM. Because of the back-emf waveform, the power density of the BDCM is 1.15 times that of the PMSM [10]; however, the harmonic content of the trapezoidal waveform is much higher. Recent laboratory tests at the PEEMRC suggest that these harmonics generate sufficient heat in the rotor to cause demagnetization. This problem, which has also been encountered in the commercial vendor sector, is being investigated at ORNL's PEEMRC.

A motor's developed power is inversely proportional to the inductance of the stator coil. The rated current, which is a control parameter of the motor that should not be exceeded, is also inversely proportional to the inductance. Rated power defines the upper bound for the inductance because any larger inductance cannot deliver rated power. Rated current, which may lead to overheating and demagnetization if exceeded, defines the lower bound for inductance.

For both the BDCM and the PMSM, the primary factor limiting the ability to operate at high constant power speed ratios (CPSRs) is the armature winding inductance. The field weakening of these two classes differs, and each is discussed separately below. Explicit formulas are developed for each machine type to show the limitation that inductance places on CPSR. The analysis neglects second order effects such as speed-sensitive losses, which include friction, windage, hysteresis, eddy currents, and skin effect in winding resistance. These speed-sensitive losses will limit the CPSR of any practical motor to a finite value.

\subsection{IMPACT OF INDUCTANCE ON THE CPSR OF THE BDCM (TRAPEZOIDAL BACK-EMF)}

Two control methods have been developed to drive the BDCM through a wide CPSR. The first method, CPA, was developed by UQM. This method uses the conventional voltage source inverter (VSI) to drive the motor. The second method, DMIC, uses a special inverter configuration that interfaces the common VSI output to the motor through an ac voltage controller composed of six silicon-controlled rectifiers (SCRs) (two anti-parallel devices in each phase). Between zero speed and base speed, there is little functional difference between the two methods. Both use well-established current regulation at low speed. Above base speed, the two methods differ substantially in how the motor current is controlled. DMIC works well for lowinductance motors, while the CPA is applicable for high-inductance motors. High-speed operation using each method is summarized, and formulas are given to show the dependence of CPSR capability on inductance.

\subsection{BOUNDING INDUCTANCES FOR CPA}

When the analysis of CPA is based on a per-phase fundamental phasor model (Fig. 2), the equation for power delivered is 


$$
\mathrm{P}=\frac{36 \mathrm{~V}_{\mathrm{dc}} \mathrm{E}_{\mathrm{b}}}{\pi^{3} \Omega_{\mathrm{b}} \mathrm{L}} \sin \delta,
$$

where

$\mathrm{V}_{\mathrm{dc}} \quad$ is the dc supply voltage,

$\mathrm{E}_{\mathrm{b}} \quad$ is the back emf.

$\Omega_{\mathrm{b}} \quad$ is the base speed in electrical radians/s,

$\mathrm{L} \quad$ is the inductance, and

$\delta \quad$ is the inverter lead angle related to the advance angle, $\Theta_{\mathrm{a}}$, by $\delta=\Theta_{\mathrm{a}}-30^{\circ}$.

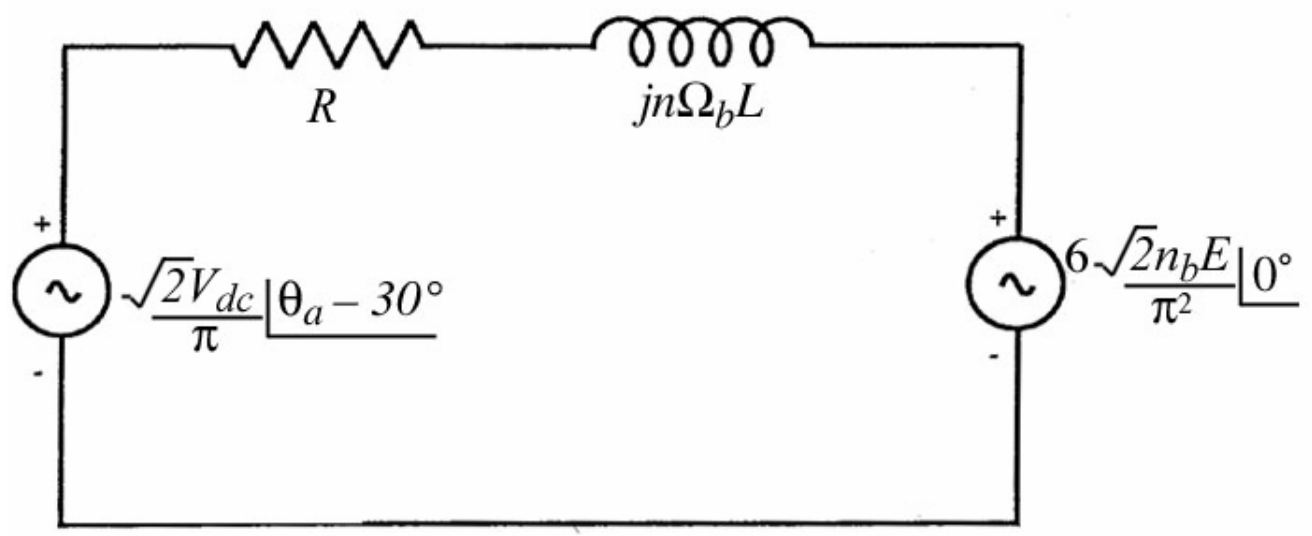

Fig. 2. Per-phase fundamental phasor model of trapezoidal back-emf used to analyze CPA at high speed.

Equation (1) may be solved for the inverter lead angle that will yield rated power as

$$
\delta=\sin ^{-1}\left[\frac{\pi^{3} \Omega_{\mathrm{b}} \mathrm{LP}_{\mathrm{r}}}{36 \mathrm{~V}_{\mathrm{dc}} \mathrm{E}_{\mathrm{b}}}\right] .
$$

Regeneration requirements may necessitate a power higher than rated power so that the right side of Eq. (1) must exceed $\mathrm{P}_{\mathrm{r}}$. This leads directly to the upper bound on inductance,

$$
\mathrm{L}_{\max }^{\mathrm{CPA}-\mathrm{BDCM}}=\frac{36 \mathrm{~V}_{\mathrm{dc}} \mathrm{E}_{\mathrm{b}}}{\pi^{3} \Omega_{\mathrm{b}} \mathrm{P}_{\mathrm{r}}} .
$$

The rated current, $\mathrm{I}_{\mathrm{r}}$, imposes a significant constraint on the motor inductance by the equation

$$
\mathrm{I}_{\mathrm{r}} \geq \frac{\sqrt{\frac{2 \mathrm{~V}_{\mathrm{dc}}^{2}}{\mathrm{CPSR}^{2}}+\frac{72 \mathrm{E}_{\mathrm{b}}^{2}}{\pi^{2}}-\frac{24 \mathrm{E}_{\mathrm{b}} \mathrm{V}_{\mathrm{dc}}}{\pi \mathrm{CPSR}} \cos \delta}}{\pi \Omega_{\mathrm{b}} \mathrm{L}} .
$$


This leads directly to a lower bound for the inductance,

$$
\mathrm{L}_{\min }^{\mathrm{CPA}-\mathrm{BDCM}} \geq \frac{\sqrt{\frac{2 \mathrm{~V}_{\mathrm{dc}}^{2}}{\mathrm{CPSR}^{2}}+\frac{72 \mathrm{E}_{\mathrm{b}}^{2}}{\pi^{2}}-\frac{24 \mathrm{E}_{\mathrm{b}} \mathrm{V}_{\mathrm{dc}}}{\pi \mathrm{CPSR}} \cos \delta}}{\pi \Omega_{\mathrm{b}} \mathrm{I}_{\mathrm{r}}} .
$$

At high speeds where CPSR $\rightarrow \infty$, an infinite CPSR is achieved when the inductance is greater than

$$
\mathrm{L}_{\mathrm{CPSR} \rightarrow \infty}^{\mathrm{CPA}-\mathrm{BDCM}}=\frac{6 \sqrt{2} \mathrm{E}_{\mathrm{b}}}{\pi^{2} \Omega_{\mathrm{b}} \mathrm{I}_{\mathrm{r}}}
$$

For $\mathrm{V}_{\mathrm{dc}}=190 \mathrm{~V}, \mathrm{E}_{\mathrm{b}}=74.2 \mathrm{~V}, \mathrm{I}_{\mathrm{r}}=203 \mathrm{~A}, \Omega_{\mathrm{b}}=1634$ electrical $\mathrm{rad} / \mathrm{sec}$, and $\mathrm{P}_{\mathrm{r}}=37000 \mathrm{~W}$, the values of $\mathrm{L}_{\max }=269 \mu \mathrm{H}$ and $\mathrm{L}_{\infty}=192 \mu \mathrm{H}$ may be calculated directly from Eqs. (3) and (6). The value of $\mathrm{L}_{\min }=164 \mu \mathrm{H}$ may be calculated by iterating between Eqs. (2) and (5).

\subsection{BOUNDING INDUCTANCES FOR DMIC}

The differential equations that govern the BDCM driven by DMIC have been solved analytically [1] for CPSR $\geq 2$. This analytic solution led to formulae for the average motor power and the rms motor current,

$$
\mathrm{P}=\frac{2 \mathrm{~V}_{\mathrm{dc}} \mathrm{E}_{\mathrm{b}}}{\pi^{2} \Omega_{\mathrm{b}} \mathrm{L}}\left[\theta_{\mathrm{a}}^{3}+\pi \theta_{\mathrm{a}}^{2}+\frac{\pi^{2}}{3} \theta_{\mathrm{a}}-\frac{2 \pi^{3}}{27}\right]
$$

and

$$
I_{r m s}=\frac{E_{b}}{\Omega_{b} L} \sqrt{\frac{8}{5 \pi^{3}} \theta_{a}^{5}+\frac{8}{3 \pi_{2}} \theta_{a}^{4}+\frac{16}{9 \pi} \theta_{a}^{3}+\frac{4}{27} \theta_{a}^{2}-\frac{16 \pi}{81} \theta_{a}+\frac{23 \pi^{2}}{1215}}
$$

where $\theta_{\mathrm{a}}$ is the advance thyristor firing angle measured from the intersection of the dc voltage with the line-to-neutral back-emf, as shown in Fig. 3. Note that $\mathrm{I}_{\mathrm{rms}}$ is independent of the dc supply voltage and motor speed. This means that once the advance, $\theta_{\mathrm{a}}$, is determined to deliver power, the same advance is used to calculate a fixed rms current that delivers that power for all speeds above CPSR $\geq 2$. The advance that delivers rated power also determines the rated rms current, which will support that power delivery regardless of speed range from CPSR $=2$ to infinite CPSR under DMIC. Of course, resistance and losses determine the actual CPSR. 

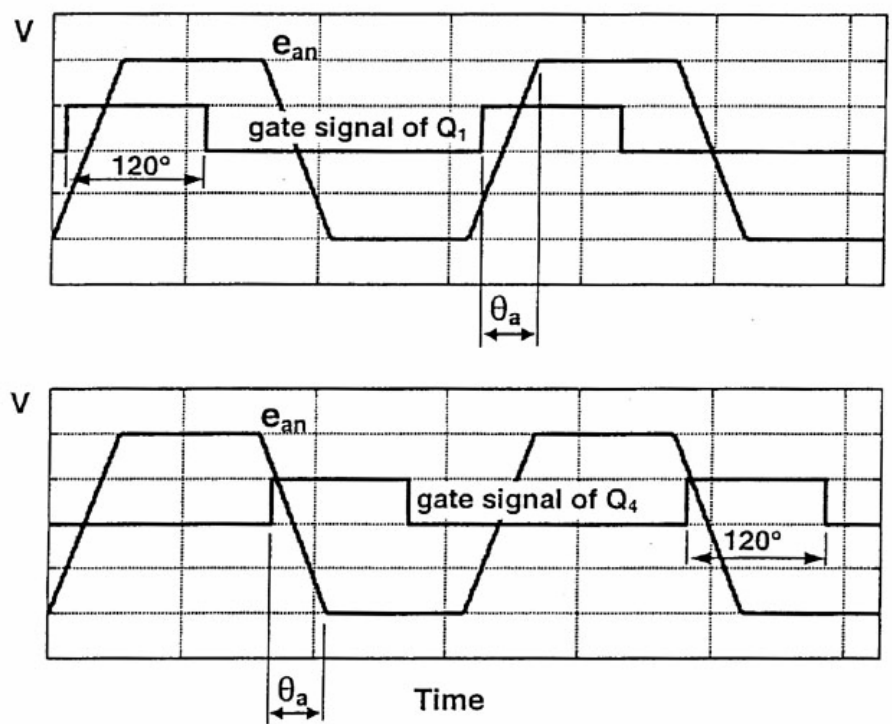

Fig. 3. Transistor firing scheme and definition of $\theta_{\mathrm{a}}$.

The smallest advance, $\theta_{\mathrm{a}}=\pi / 6$, determines the lower bound of inductance as

$$
\mathrm{L}_{\min }^{\text {DMIC-BDCM }}=\frac{\pi \mathrm{E}_{\mathrm{b}}}{\Omega_{\mathrm{b}} \mathrm{I}_{\mathrm{r}} \sqrt{1620}}
$$

The largest advance, $\theta_{\mathrm{a}}=\pi / 3$, determines the upper bound of inductance as

$$
\mathrm{L}_{\text {max }}^{\text {DMIC-BDCM }}=\frac{\pi \mathrm{E}_{\mathrm{b}}}{\Omega_{\mathrm{b}} \mathrm{I}_{\mathrm{r}}} \sqrt{\frac{91}{1215}} .
$$

The ratio of $\mathrm{L}_{\max }$ to $\mathrm{L}_{\min }$ is 11.0 , which gives the motor designer a wide target inductance range.

If one substitutes the same parameters used to calculate the CPA inductances $\left(\mathrm{V}_{\mathrm{dc}}=190 \mathrm{~V}, \mathrm{E}_{\mathrm{b}}=\right.$ $74.2 \mathrm{~V}, \mathrm{I}_{\mathrm{r}}=203 \mathrm{~A}, \Omega_{\mathrm{b}}=1634$ electrical $\mathrm{rad} / \mathrm{sec}$, and $\left.\mathrm{P}_{\mathrm{r}}=37000 \mathrm{~W}\right)$, the values of $\mathrm{L}_{\min }=17.5 \mu \mathrm{H}$ and $\mathrm{L}_{\max }=192 \mu \mathrm{H}$ may be calculated directly from Eqs. (11) and (12).

\subsection{BOUNDING INDUCTANCES FOR THE PMSM (SINUSOIDAL BACK-EMF)}

When the analysis of CPA is based on the per phase phasor model shown in Fig. 4 for sinusoidal voltage waveforms, the equation for power delivered is

$$
\mathrm{P}=\frac{3 \mathrm{~V}_{\max } \mathrm{E}_{\mathrm{b}}}{\Omega_{\mathrm{b}} \mathrm{L}} \sin \delta
$$


ORNL 2002-03422/jcn

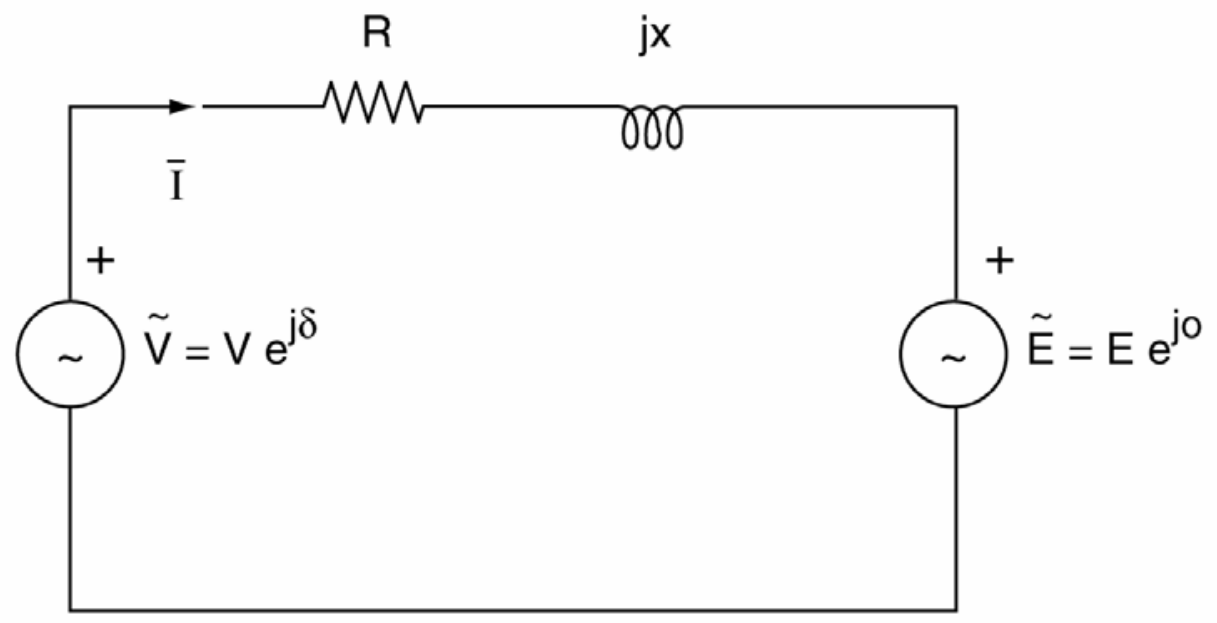

Fig. 4. Per-phase phasor model of sinusoidal back-emf used to analyze CPA at high speed.

The value of $\mathrm{V}$ in the model is $\mathrm{V}_{\max }$ and it is related to $\mathrm{V}_{\mathrm{dc}}$ if over modulation is allowed by $\mathrm{V}_{\mathrm{dc}}=\frac{\pi}{\sqrt{2}} \mathrm{~V}_{\max }$.

The expression for power shows that it is easy to control the PMSM to deliver required power above base speed, just as it did for the BDCM. All that is necessary is that the inverter lead angle, $\delta$, be held fixed so that the required power is delivered. The equation is

$$
\delta=\sin ^{-1}\left(\frac{\mathrm{X}_{\mathrm{b}} \mathrm{P}}{3 \mathrm{~V}_{\max } \mathrm{E}_{\mathrm{b}}}\right)=\cos ^{-1}\left(\frac{\mathrm{E}_{\mathrm{b}}}{\mathrm{V}_{\max }}\right),
$$

where $\mathrm{X}_{\mathrm{b}}$ is the inductive reactance, $\Omega_{\mathrm{b}} \mathrm{L}$. The expression on the far right of Eq. (12) is obtained by substituting the equality,

$$
\mathrm{P}_{\mathrm{r}}=3 \mathrm{E}_{\mathrm{b}} \mathrm{I}_{\mathrm{r}}
$$

in the center expression of Eq. (12) and recognizing that $\mathrm{E}_{\mathrm{b}}$ is $90^{\circ}$ out of phase with the inductor voltage. Equation (13) is true because at base speed, the sum of the power developed in each phase at rated current is the rated power of the motor, and the current is in phase with the backemf.

While constant lead angle control allows the PMSM to operate at constant power above base speed, it is not a certainty that that it will operate within the rated current. Neglecting the armature resistance, the equation for phasor current in Fig. 4 is

$$
\overline{\mathrm{I}}=\frac{\mathrm{V}_{\max } \mathrm{e}^{\mathrm{j} \delta}-\mathrm{E}_{\mathrm{b}}}{\mathrm{jnX} \mathrm{X}_{\mathrm{b}}},
$$


which has rms magnitude

$$
I_{\mathrm{rms}}=\frac{\sqrt{\mathrm{V}_{\max }^{2}-\mathrm{n} \cdot 2 \mathrm{~V}_{\max } \mathrm{E}_{\mathrm{b}} \cos \delta+\mathrm{n}^{2} \mathrm{E}_{\mathrm{b}}^{2}}}{n X_{\mathrm{b}}}
$$

Recall that $\mathrm{n}$ is the ratio,

$$
\mathrm{n}=\mathrm{N} / \mathrm{N}_{\mathrm{b}}
$$

where

$\mathrm{N}$ is the mechanical angular speed, rpm, and

$\mathrm{N}_{\mathrm{b}}$ is the mechanical angular base speed in rpm.

Equation (15) gives the rms motor current, $\mathrm{I}_{\mathrm{rms}}$, when operating at any speed above base speed. Substituting the lead angle from the right side of Eq. (12) so that rated power is produced, and requiring that the rms current be less than the rated current at maximum speed where $n$ equals the CPSR, leads to the equation for bounding current,

$$
\mathrm{I}_{\mathrm{r}} \geq \frac{\sqrt{\mathrm{V}_{\max }^{2}+\operatorname{CPSR}(\operatorname{CPSR}-2) \mathrm{E}_{\mathrm{b}}^{2}}}{\operatorname{CPSR} \Omega_{\mathrm{b}} \mathrm{L}}
$$

Equation (17) may be solved directly for the lower bound on inductance to satisfy the rated current limit,

$$
\mathrm{L}_{\min }^{\mathrm{CPA}-\mathrm{PMSM}} \geq \frac{\sqrt{\mathrm{V}_{\max }^{2}+\mathrm{CPSR}(\mathrm{CPSR}-2) \mathrm{E}_{\mathrm{b}}^{2}}}{\operatorname{CPSR} \Omega_{\mathrm{b}} \mathrm{I}_{\mathrm{r}}}
$$

The limit of Eq. (18) as CPSR approaches infinity shows that an infinite CPSR can be achieved provided that the motor inductance is greater than

$$
\mathrm{L}_{\mathrm{CPSR} \rightarrow \infty}^{\mathrm{CPA}-\mathrm{PMSM}} \geq \frac{\mathrm{E}_{\mathrm{b}}}{\Omega_{\mathrm{b}} \mathrm{I}_{\mathrm{r}}}
$$

The upper bound is obtained by recognizing that the lead angle in Eq. (11) cannot exceed $90^{\circ}$. Again, by using the equality of Eq. (13), one may calculate the upper bound to inductance,

$$
\mathrm{L}_{\max }=\frac{3 \mathrm{~V}_{\max } \mathrm{E}_{\mathrm{b}}}{\mathrm{P}_{\mathrm{r}} \Omega_{\mathrm{b}}}=\frac{\mathrm{V}_{\max }}{\Omega_{\mathrm{b}} \mathrm{I}_{\mathrm{r}}} .
$$


If one substitutes the values $\mathrm{V}_{\mathrm{dc}}=190 \mathrm{~V}$ so that $\mathrm{Vmax}=85.54 \mathrm{~V}$ (assuming over-modulation), $\mathrm{E}_{\mathrm{b}}=74.2 / \sqrt{2} \mathrm{~V}, \mathrm{I}_{\mathrm{r}}=203 \mathrm{~A}, \Omega_{\mathrm{b}}=1634$ electrical rad/sec, $\mathrm{P}_{\mathrm{r}}=37000 \mathrm{~W}$, and CPSR $=9$, the values of $\mathrm{L}_{\min }=142 \mu \mathrm{H}, \mathrm{L}_{\infty}=158 \mu \mathrm{H}$, and $\mathrm{L}_{\max }=164 \mu \mathrm{H}$ may be calculated directly from Eqs. (18), (19), and (20). 


\section{DMIC MINIMIZES CURRENT IN PMSMs AND BDCMs}

At any power level, the SCRs, which are the heart of the DMIC as shown in Fig. 1., enable maximum watts per rms amp control during constant power operation by minimizing rms current [11]. This feature is not possible with a VSI-driven motor, which has no SCRs and a fixed inductance. In addition, losses can be substantially reduced using DMIC operation of PMSMs whose inductance is sufficiently large for VSI control (no SCRs) to achieve infinite CPSR. This current minimization was determined in addressing this question: Assuming that the supply voltage can deliver the desired useful power, and neglecting the resistance, is there a value of inductive reactance, $X_{b}=n \Omega_{b} L$, that minimizes the current? The answer is yes, and the equation for that inductive reactance is

$$
\mathrm{X}_{\min \mathrm{I}}=\mathrm{n} \Omega_{\mathrm{b}} \mathrm{L}=\frac{3 \mathrm{~V}_{\max }}{\mathrm{P}} \sqrt{\mathrm{n}^{2} \mathrm{E}_{\mathrm{b}}^{2}-\mathrm{V}_{\max }^{2}},
$$

which may be solved for the inductance needed at that electrical frequency, $\mathrm{n} \Omega_{\mathrm{b}}$. $\mathrm{P}$ is the developed power, $V_{\max }$ is the supply voltage, $\mathrm{n}$ is the relative mechanical speed, and $\omega$ is the electrical rad/s. With the optimal value of thyristor reactance, the minimum rms motor current is

$$
I_{\min }=\frac{P}{3 V_{\text {max }}}=\frac{P}{3 \sqrt{E_{b}^{2}+\left(X_{b} I_{r}\right)^{2}}} .
$$

Equation (22) is independent of speed and directly proportional to developed power. If one substitutes the equality from Eq. (13) and the motor inductance for infinite CPSR from Eq. (19) for $\mathrm{X}_{\mathrm{b}}$ into Eq. (22), a linear relation in $\mathrm{P}$ emerges,

$$
\frac{I_{\min }}{I_{\mathrm{r}}}=\frac{P}{\sqrt{2} P_{r}}
$$

It can also be shown that the motor current is in phase with the inverter voltage phasor, which means that the inverter operates at unity power factor.

Figure 4 is a comparison of the motor current under CPA control with the motor current under DMIC. The linear relation between the current and power of Eq. (23) is plotted at the bottom. As shown in Ref. [11], Eq. (17) with the inductance for infinite CPSR from Eq. (19), $V_{\max }=E_{b} \sqrt{2}$, $\mathrm{P}_{\max }=\mathrm{P}_{\mathrm{r}} \sqrt{2}, \sin \delta=\mathrm{P} /\left(\mathrm{P}_{\mathrm{r}} \sqrt{2}\right)$, and $\cos \delta=\sqrt{1-\sin ^{2} \delta}$ lead to the rms motor current equation,

$$
I=I_{r} \sqrt{\frac{n^{2}-2 n \sqrt{2-\left(\frac{P}{P_{r}}\right)^{2}}+2}{n^{2}}} .
$$




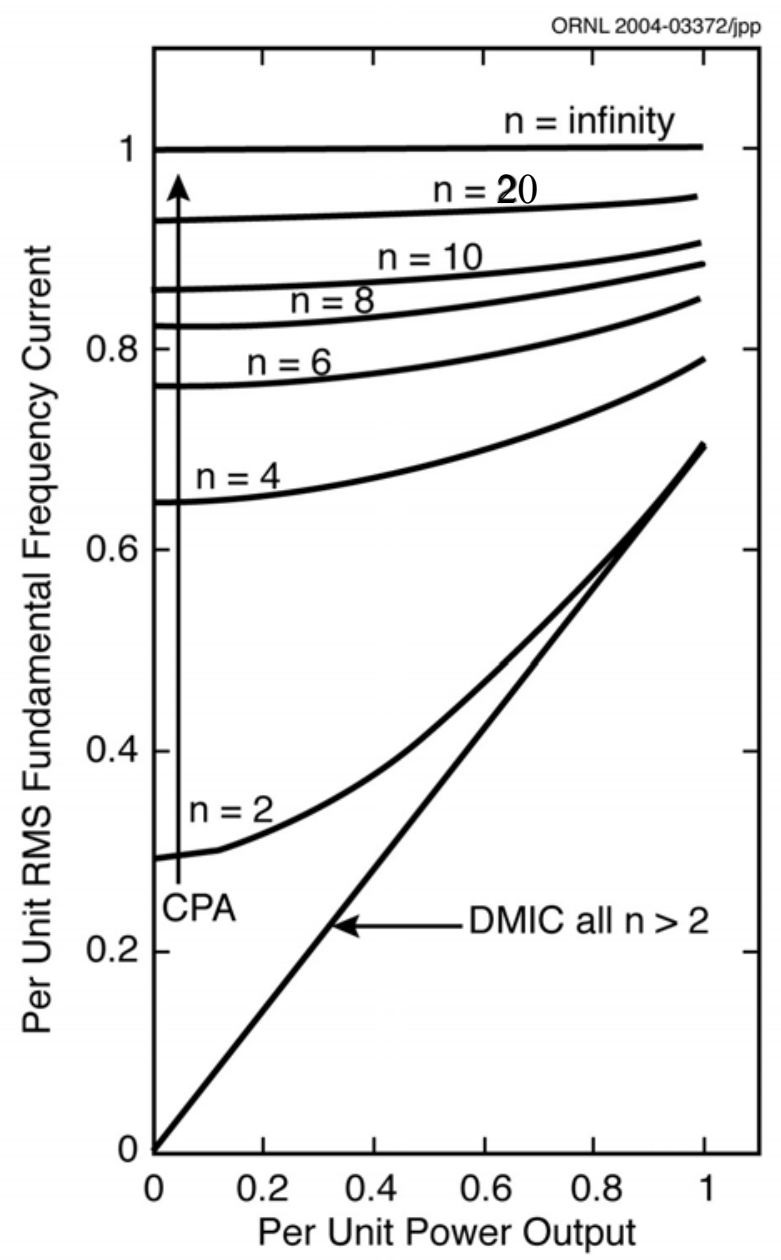

Fig. 5. Constant power operation of a PMSM comparing CPA control with DMIC.

Figure 5 is a plot of Eq. (24) in the form of $\mathrm{I} / \mathrm{I}_{\text {rated }}$ versus $\mathrm{P} / \mathrm{P}_{\mathrm{r}}$ for $\mathrm{n}$ values of 2, 4, 6, 8, 10, 20, and $\infty$. The figure shows that when $\mathrm{L}=\mathrm{L}_{\infty}$, any developed power up to the rated power can be achieved without exceeding the rms current rating of the motor. The flatness of the CPA curves indicates that the copper losses in the motor are virtually independent of the developed power. Efficiency may be poor when operating conditions require a developed power less than the rated power. The reduction in copper losses in DMIC can be applied to compensate for the increased losses in the SCRs; and when there is a net reduction in total inverter plus motor losses, that reduction can be applied over the operating life of the drive toward the added initial cost of the SCRs.

This type of analysis provides a relationship showing the current that may be saved at various operating speeds by using one controller (DMIC) instead of another (CPA or vector control) so that operational cost benefit estimates may be made based on the application's expected duty cycle. In any life-cycle cost study, this information, which is not the first or initial cost, must be included because it can provide significant benefits to the customer. 


\section{MOTOR AND INVERTER COST STUDY}

There are several ways to increase the inductance, L, of a PM motor. One, which is clumsy and wasteful, is to add an inductor in each of the three phases. Justifying the additional cost of the six thyristors required by the DMIC, with the cost penalty of adding inductors in each phase, is not difficult. A second method is to attempt to increase the inductance in the stator windings of the design. The University of Wisconsin, Madison (T. Jahns), and ORNL (J. M. Bailey) are conducting research to increase the inductance by means of concentrated windings; however, by using ORNL's radial-gap design tool for radial-gap PM motors, we found that a reasonable range of inductance could be designed into the PM motors.

Seven motor designs that have been concocted using the design code, with phase inductances ranging from 1270 to $97 \mu \mathrm{H}$, are summarized in Table 1. Each motor was designed to deliver $30 \mathrm{~kW}$ at $1500 \mathrm{rpm}$ with the maximum current density in the wires held at about $13 \mathrm{~A} / \mathrm{mm}^{2}$. Motors 1 and 2 had inductances large enough to be driven with CPS. Motors 3 and 4 required DMIC to drive them. Motors 5, 6, and 9 were used to illustrate internal consistency in the motor costs predicted by the design code, but were not part of the inverter/motor systems cost analysis.

Two equations illustrate the internal consistency of Table 1. The first is the equation for torque:

$$
\mathrm{T}=\frac{30 \bullet 2 \mathrm{E}_{\mathrm{b}} \mathrm{I}^{\text {peak }}}{\pi \Omega_{\mathrm{rpm}}} .
$$

The second is for back-emf:

$$
\mathrm{E}_{\mathrm{b}}=\mathrm{N}_{\mathrm{m}} \mathrm{B}_{\mathrm{g}} \mathrm{n}_{\mathrm{s}} \mathrm{L}_{\mathrm{st}} \frac{2 \pi \Omega_{\mathrm{rpm}}}{60} \mathrm{R}_{\mathrm{ro}},
$$

where

$$
\begin{array}{ll}
N_{m} & \text { is the number of poles, } \\
B_{g} & \text { is the magnetic field strength, } \\
L_{s t} & \text { is the length of the stator, } \\
\mathrm{I}_{\text {peak }} & \text { is the maximum current, } \\
\Omega_{\text {rpm }} & \text { is the mechanical rotational speed, and } \\
R_{r o} & \text { is the outer radius of the rotor. }
\end{array}
$$

Case 2 reduces the Case 1 inductance by cutting the turns per slot in half, which reduces the back-emf. The current must be doubled to maintain torque. This requires that the conducting area be doubled to maintain the current density. Reduction of the wire length and an increase in area should reduce the wire resistance by $1 / 4$. Case 3 doubles the stator length, which doubles the back-emf. Current must decrease by $1 / 2$ to maintain torque. This requires that the conducting area be decreased by $1 / 2$ to maintain the current density. Recognizing that doubling the stator length is roughly like increasing the wire length by $4 / 3$ (not 2 because of the end turns), one may estimate the increase in resistance as the product of $4 / 3$ and 2 from the area reduction. 
Table 1. Motor designs investigated for motor cost study

\begin{tabular}{|c|c|c|c|c|c|c|c|}
\hline Case & $\# 1$ & \#2 & \#3 & \#4 & $\# 5$ & \#6 & $\# 9$ \\
\hline Power, W & 30000 & 30000 & 30000 & 30000 & 30000 & 30000 & 30000 \\
\hline Torque, N-m & 191 & 191 & 191 & 191 & 191 & 191 & 191 \\
\hline Speed, rpm & 1500 & 1500 & 1500 & 1500 & 1500 & 1500 & 1500 \\
\hline OR stator $R_{\mathrm{so}}$, in & 5 & 5 & 5 & 5 & 6.5 & 6.5 & 6.5 \\
\hline OR rotor, $\mathrm{R}_{\mathrm{ro}}$, in. & 3 & 3 & 3 & 3 & 3 & 3 & 3 \\
\hline IR rotor, $\mathrm{R}_{\mathrm{ri}}$, in. & 2.453 & 2.453 & 2.453 & 2.453 & 2.009 & 2.009 & 2.009 \\
\hline Stack length, $L_{s t}$, in. & 1.969 & 1.969 & 3.938 & 3.938 & 3.938 & 3.938 & 3.938 \\
\hline Terminal voltage, $\mathrm{V}$ & 308 & 154 & 305 & 152 & 290 & 146 & 73 \\
\hline Lawler $\mathrm{V}_{\mathrm{dc}}, \mathrm{V}$ & 529.31 & 264.26 & 412.81 & 205.77 & 417.79 & 209.26 & 104.65 \\
\hline No. magnets & 18 & 18 & 18 & 18 & 8 & 8 & 8 \\
\hline Omega $_{b}$, electrical rad $/ \mathrm{s}$ & 1413.72 & 1413.72 & 1413.72 & 1413.72 & 628.3 & 628.3 & 628.3 \\
\hline $\mathrm{T}_{\mathrm{c}}$, turns/coil & 8 & 4 & 4 & 2 & 8 & 4 & 2 \\
\hline $\mathrm{T}_{\mathrm{s}}$, turns/slot & 16 & 8 & 8 & 4 & 16 & 8 & 4 \\
\hline $\begin{array}{l}\text { line-to-neutral back-emf at } \\
\text { base speed, } E_{b}\end{array}$ & 147.06 & 73.53 & 147.06 & 73.38 & 138.52 & 69.26 & 34.63 \\
\hline$I_{\text {peak }}=P /\left(2 E_{b}\right), A$ & 102 & 204 & 102 & 204.42 & 108.29 & 216.58 & 433.15 \\
\hline$I_{r m s}=\operatorname{sqrt}(2 / 3) I_{\text {peak }}$ & 83.28 & 166.56 & 83.28 & 166.90 & 88.42 & 176.83 & 353.67 \\
\hline Phase Inductance, L, uH & 1270 & 316 & 624 & 156 & 1560 & 390 & 97 \\
\hline Phase resistance, $\mathrm{R}$, ohms & 0.0673 & 0.0168 & 0.0497 & 0.0115 & 0.0592 & 0.0159 & 0.004 \\
\hline wire gage & 16 & 16 & 16 & 16 & 16 & 16 & 16 \\
\hline wires per turn & 6 & 12 & 6 & 13 & 7 & 13 & 26 \\
\hline wire area, $\mathrm{mm}^{2}$ & 1.308 & 1.308 & 1.308 & 1.308 & 1.308 & 1.308 & 1.308 \\
\hline Copper area in slot, $\mathrm{mm}^{2}$ & 133 & 133 & 79 & 69 & 151 & 140 & 140 \\
\hline Current Density, A/mm² & 13.00 & 13.00 & 13.25 & 12.25 & 12.02 & 12.84 & 12.94 \\
\hline $\mathrm{L}_{\min }^{\mathrm{DMIC}}, \mathrm{uH}$ & 97 & 24 & 97 & 24 & 195 & 49 & 12 \\
\hline $\mathrm{L}_{\text {no cont. cur }}^{\mathrm{DMIC}} \mathrm{uH}$ & 839 & 210 & 839 & 209 & 1674 & 419 & 105 \\
\hline $\mathrm{L}_{\max }^{\mathrm{DMIC}}, \mathrm{uH}$ & 1074 & 268 & 1074 & 267 & 2144 & 536 & 134 \\
\hline \multicolumn{8}{|c|}{ The following inductance bounds use Lawler's Vdc which is best when L>LDMICmax } \\
\hline $\mathrm{L}_{\min }^{\mathrm{CPA}}, \mathrm{uH}$ for $\mathrm{CPSR}=4$ & 568 & 142 & 679 & 169 & 1297 & 324 & 81 \\
\hline $\mathrm{L}^{\mathrm{CPA}}{ }_{\text {inf., }}, \mathrm{uH}$ & 1074 & 268 & 1074 & 267 & 2144 & 536 & 134 \\
\hline $\mathrm{L}_{\max }^{\mathrm{CPA}}, \mathrm{uH}$ & 2131 & 532 & 1662 & 413 & 3565 & 893 & 223 \\
\hline
\end{tabular}

Case 4 relates to Case 3 like Case 2 relates to Case 1. Cases 5, 6, and 9 which are not used in the cost study, are all at the same length and show the effect on inductance as turns-per-slot variation is compensated by wires per turn to maintain current density. Note that the stator radius of the last three cases is larger, which is the reason for their higher costs, as discussed later under Table 2.

Additional important design outputs beyond the calculations summarized in Table 1 are the volume and weight of the rotor steel laminates, the stator steel laminates, the magnets, and the copper, from which material costs are estimated. Two 0.5-in-thick steel disks connected the rotor to a 1.5-in.-dia steel shaft. The shaft extended beyond the stack length by 4 in. A 0.5 -in.thick cylindrical aluminum housing extended 0.5 in. beyond the stator at each end and was enclosed at each end by equally thick aluminum end disks flush with the edge of the cylinder. The number of 0.0185 -in.-thick steel laminates was determined by dividing the stacking factor 
corrected length by the thickness of a laminate. Since the rotor and stator are punched from a single laminate, cost per laminate was apportioned to the rotor and stator by weight fraction. Table 2 shows the material weight of the magnets, rotor laminates, shaft, connecting disks, stator laminates, copper wire, and aluminum housing.

Table 2. Weight of components in motor cost study

\begin{tabular}{|c|c|c|c|c|c|c|c|}
\hline Case & $\# 1$ & $\# 2$ & \#3 & $\# 4$ & $\# 5$ & \#6 & $\# 9$ \\
\hline Magnet mass, Ib & 2.15 & 2.15 & 4.30 & 4.29 & 4.45 & 4.45 & 4.45 \\
\hline Rotor laminates, lb & 2.79 & 2.79 & 5.58 & 5.57 & 12.38 & 12.38 & 12.38 \\
\hline 1.5-in.-dia steel shaft, Ib. & 2.93 & 2.93 & 3.90 & 3.90 & 3.90 & 3.90 & 3.90 \\
\hline $\begin{array}{l}\text { Two 0.5-in. thick steel } \\
\text { connecting disks, Ib }\end{array}$ & 4.76 & 4.76 & 4.76 & 4.76 & 3.03 & 3.03 & 3.03 \\
\hline Stator laminates, lb & 14.90 & 14.90 & 29.80 & 29.74 & 66.30 & 66.30 & 66.30 \\
\hline Copper, lb & 13.90 & 13.90 & 10.28 & 11.12 & 16.64 & 15.45 & 15.45 \\
\hline 0.5-in.thick Al cyl housing, lb & 4.90 & 4.90 & 8.14 & 8.14 & 10.47 & 10.47 & 10.47 \\
\hline Two 0.5-in Al end disks, lb & 7.68 & 7.68 & 7.68 & 7.68 & 13.10 & 13.10 & 13.10 \\
\hline
\end{tabular}

Table 3 summarizes the SPM motor costs. It includes material, labor, and overhead (25\% of material cost), and cooling system penalty cost (10\% of material plus labor and overhead) as the major elements of manufacturing costs. The original equipment manufacturer (OEM) price adds $10 \%$ for profit margin to the manufacturing cost.

Table 3. Cost comparison of PM motors with surface-mounted magnets

\begin{tabular}{|c|c|c|c|c|c|c|c|c|}
\hline $\begin{array}{l}\text { cost } / \mathrm{lb} \\
\text { or } \%\end{array}$ & Case & \#1 & \#2 & \#3 & \#4 & \#5 & \#6 & \#9 \\
\hline & Cost per laminate, $\$$ & 0.41 & 0.41 & 0.41 & 0.41 & 0.63 & 0.63 & 0.63 \\
\hline \multirow[t]{2}{*}{$\$ 14.50$} & Magnet matl., $\$ / \mathrm{lb}$ & $\$ 31.18$ & $\$ 31.18$ & $\$ 62.35$ & $\$ 62.21$ & $\$ 64.53$ & $\$ 64.53$ & $\$ 64.53$ \\
\hline & 0.0185-in. M19 rotor lamins. & $\$ 6.68$ & $\$ 6.68$ & $\$ 13.35$ & $\$ 13.35$ & $\$ 20.47$ & $\$ 20.47$ & $\$ 20.47$ \\
\hline$\$ 1.80$ & Rotor shaft, $\$ / l b$ & $\$ 5.27$ & $\$ 5.27$ & $\$ 7.01$ & $\$ 7.01$ & $\$ 7.01$ & $\$ 7.01$ & $\$ 7.01$ \\
\hline \multirow[t]{2}{*}{$\$ 0.50$} & Rotor support disks, $\$ / \mathrm{lb}$ & $\$ 2.38$ & $\$ 2.38$ & $\$ 2.38$ & $\$ 2.38$ & $\$ 1.52$ & $\$ 1.52$ & $\$ 1.52$ \\
\hline & 0.0185-in. M19 stator lamins. & $\$ 35.65$ & $\$ 35.65$ & $\$ 71.30$ & $\$ 71.30$ & $\$ 109.61$ & $\$ 109.61$ & $\$ 109.61$ \\
\hline$\$ 3.07$ & Copper wire, $\$ / \mathrm{lb}$ & $\$ 42.67$ & $\$ 42.67$ & $\$ 31.56$ & $\$ 34.14$ & $\$ 51.08$ & $\$ 47.43$ & $\$ 47.43$ \\
\hline$\$ 2.50$ & Cyl aluminum frame, $\$ / \mathrm{lb}$ & $\$ 12.24$ & $\$ 12.24$ & $\$ 20.36$ & $\$ 20.36$ & $\$ 26.18$ & $\$ 26.18$ & $\$ 26.18$ \\
\hline$\$ 3.00$ & Aluminum end caps, $\$ / \mathrm{lb}$ & $\$ 23.03$ & $\$ 23.03$ & $\$ 23.03$ & $\$ 23.03$ & $\$ 39.29$ & $\$ 39.29$ & $\$ 39.29$ \\
\hline $25 \%$ & Labor \& Overhead & $\$ 39.78$ & $\$ 39.78$ & $\$ 57.84$ & $\$ 58.45$ & $\$ 79.92$ & $\$ 79.01$ & $\$ 79.01$ \\
\hline \multirow[t]{3}{*}{$10 \%$} & Cooling & $\$ 19.89$ & $\$ 19.89$ & $\$ 28.92$ & $\$ 29.22$ & $\$ 39.96$ & $\$ 39.50$ & $\$ 39.50$ \\
\hline & & & & & & & & \\
\hline & Mfg. Cost & $\$ 218.77$ & $\$ 218.77$ & $\$ 318.11$ & $\$ 321.45$ & $\$ 439.57$ & $\$ 434.55$ & $\$ 434.55$ \\
\hline \multirow[t]{3}{*}{$10 \%$} & Profit Margin & $\$ 21.88$ & $\$ 21.88$ & $\$ 31.81$ & $\$ 32.15$ & $\$ 43.96$ & $\$ 43.45$ & $\$ 43.45$ \\
\hline & & & & & & & & \\
\hline & OEM Price & $\$ 240.64$ & $\$ 240.64$ & $\$ 349.92$ & $\$ 353.60$ & $\$ 483.53$ & $\$ 478.00$ & $\$ 478.00$ \\
\hline
\end{tabular}

The cost of the motor is most sensitive to magnet and copper costs. It was essential to hold the current density constant by reducing the wire-packing factor for the low-inductance motors; otherwise, much more copper would have been added to the motor costs, resulting in an additional $\$ 50$ penalty. Increasing the length adds to the magnet material, which is probably the most significant contributor to the additional cost of the low-inductance motors. The cost per unit power ranges from $\$ 4 / \mathrm{kW}$ (Cases 1 and 2) to $\$ 6 / \mathrm{kW}$ (Cases 3 and 4 ) which is in close to the FreedomCAR goal of $\$ 5 / \mathrm{kW}$. 
A simulation of the first four cases was completed to verify that the model could deliver the desired power and to guide selection of the inverter devices. The simulation provided information about the current in the motor and in the inverter while being driven by CPA and by DMIC. In addition to the voltage requirements obtained during the motor design study, current requirements are also necessary for selection of the inverter components. The upper half of Table 4 summarizes the calculated power, the peak, rms, and average currents that pass through the transistors and bypass diodes, the peak and rms currents that pass through the motor, and the rms and peak currents that pass through the dc source during CPA operation. The lower half of the table summarizes the peak, rms, and average currents that pass through the transistors and through the motor followed by the rms and peak currents through the dc source during DMIC operation. Note the absence of current in the IGBT bypass diodes under DMIC control, which earmarks the DMIC.

Table 4. Inverter and motor currents under CPA and DMIC for selection of devices in cost study

\begin{tabular}{|c|c|c|c|c|}
\hline Case & \#1 & $\# 2$ & \#3 & $\# 4$ \\
\hline $\mathrm{V}_{\mathrm{dc}}$ & 529 & 264 & 413 & 206 \\
\hline Back-emf line-to-line & 1176 & 588 & 1176 & 587 \\
\hline $\mathrm{P}_{\mathrm{CPA} \_a v g}$ & 29351 & 29190 & 29224 & 28373 \\
\hline $\mathrm{I}_{\text {CPA_transistor_peak }}$ & 67.50 & 135.00 & 141.70 & 281.50 \\
\hline $\mathrm{I}_{\mathrm{CPA} \text { _transistor_rms }}$ & 33.70 & 67.20 & 63.10 & 125.00 \\
\hline $\mathrm{I}_{\mathrm{CPA} \_ \text {transistor_avg }}$ & 20.20 & 40.30 & 34.10 & 67.70 \\
\hline ICPA_bypass_diode_peak & 28.00 & 57.50 & 107.20 & 213.80 \\
\hline$I_{\text {CPA_bypass_diode_rms }}$ & 5.00 & 10.50 & 27.40 & 55.10 \\
\hline $\mathrm{I}_{\text {CPA_bypass_diode_avg }}$ & 1.30 & 2.80 & 9.60 & 19.50 \\
\hline$I_{\text {CPA_motor_peak }}$ & 67.50 & 135.00 & 141.70 & 281.50 \\
\hline $\mathrm{I}_{\mathrm{CPA} \text { _motor_ms }}$ & 48.00 & 96.30 & 97.40 & 193.30 \\
\hline $\mathrm{I}_{\text {CPA_dcsource_rms }}$ & 56.30 & 113.70 & 79.90 & 157.40 \\
\hline $\mathrm{I}_{\text {CPA_dcsource_peak }}$ & 57.00 & 112.40 & 73.30 & 144.20 \\
\hline $\mathrm{E}_{\mathrm{CPA}}(\mathrm{n}=4)$ & 0.9722 & 0.9599 & 0.9325 & 0.9136 \\
\hline$P_{\text {DMIC_avg }}$ & 28973 & 29202 & 29901 & 28903 \\
\hline I DMIC_transistor_peak $_{1}$ & 58.00 & 117.00 & 77.80 & 150.50 \\
\hline $\mathrm{I}_{\text {DMIC_transistor_rms }}$ & 30.10 & 60.60 & 41.30 & 79.80 \\
\hline IDMIC_transistor_avg & 18.50 & 37.20 & 24.60 & 47.50 \\
\hline IDMIC_bypass_diode_peak & 0.00 & 0.00 & 0.00 & 0.00 \\
\hline IDMIC_bypass_diode_rms & 0.00 & 0.00 & 0.00 & 0.00 \\
\hline IDMIC_bypass_diode_avg & 0.00 & 0.00 & 0.00 & 0.00 \\
\hline$I_{\text {DMIC_motor_peak }}$ & 58.00 & 117.00 & 77.80 & 150.50 \\
\hline$I_{\text {DMIC_motor_ms }}$ & 42.70 & 85.60 & 58.00 & 113.10 \\
\hline $\mathrm{I}_{\text {DMIC_dcsource_rms }}$ & 56.00 & 111.60 & 73.60 & 143.10 \\
\hline IDMIC_dcsource_peak & 56.00 & 111.60 & 73.50 & 143.00 \\
\hline$E_{\text {DMIC }}(n=4)$ & 0.9709 & 0.9551 & 0.9625 & 0.9437 \\
\hline
\end{tabular}

Table 5 summarizes the sizes of the more expensive components based on the voltages in Table 1 and the currents in Table 4. 
Finally, Table 6 presents the total inverter costs based on a production volume of 10,000 units, along with indications of the sources that provided these cost estimates. It is likely that with larger volume demand in the future, the inverter costs will decline substantially. These numbers lead to a cost per unit power of $\$ 36 / \mathrm{kW}$, recognizing that the motors must deliver $55 \mathrm{~kW}$ for short periods. This is high compared with the FreedomCAR target value of $\$ 7 / \mathrm{kW}$.

Figure 6 breaks down the inverter components used in the ORNL study for a relative component cost comparison with recent studies conducted by DOE subcontractors. Figure 7 is a subcontractor's cost study based on 100,000 and shows that the relative component costs are in reasonable agreement. As one might expect the ORNL total inverter cost of $\$ 1,900$, based on 10,000 off-the-shelf items, is twice as high as the vendor cost of $\$ 933$, based on 100,000 items.
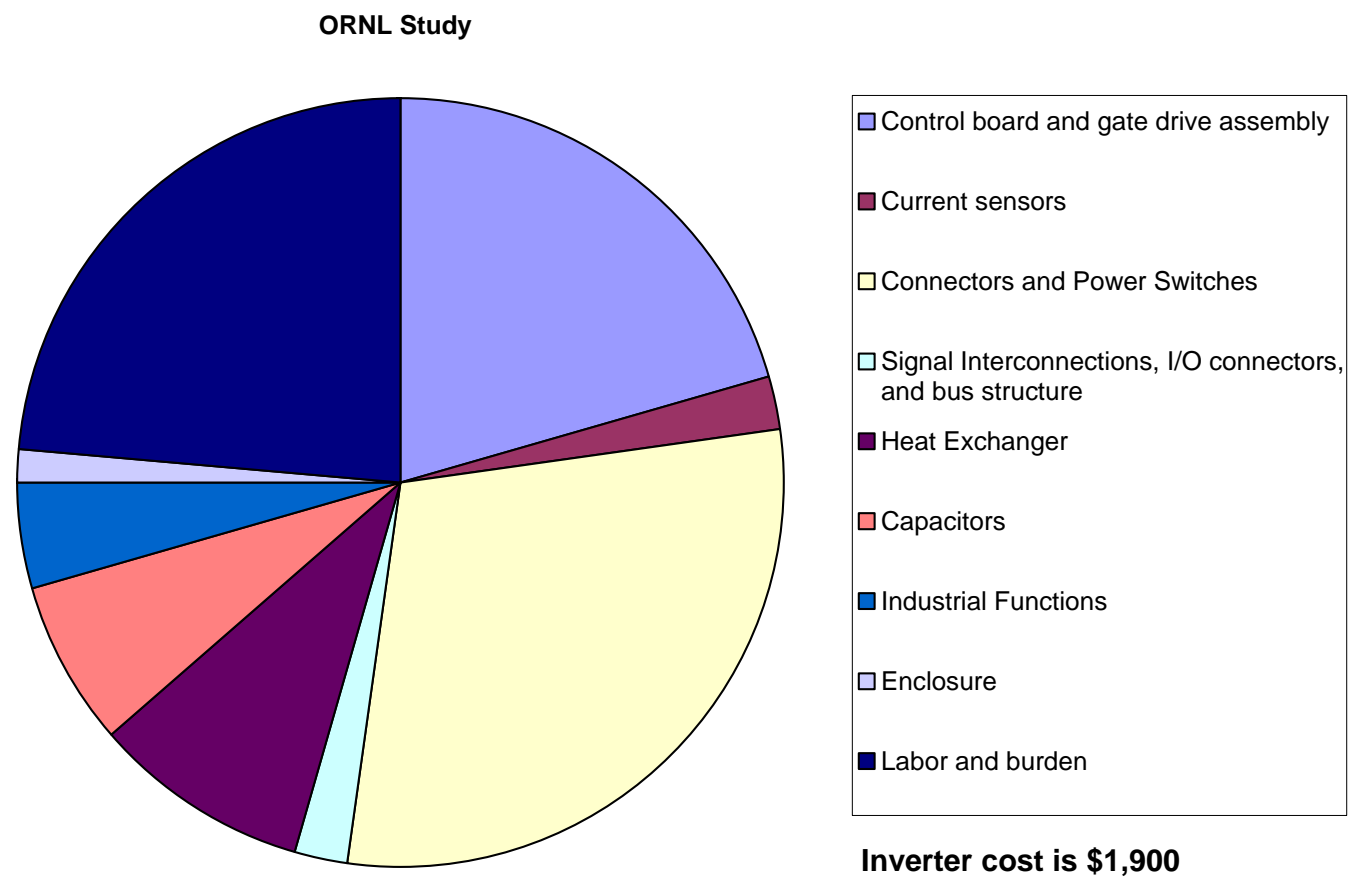

Fig. 6. Today's relative inverter component costs based on the ORNL study (10,000 units).

Figure 8 is a subcontractor's inverter cost goal, which corresponds to the FreedomCAR inverter cost goal of $\$ 7 / \mathrm{kW}$. The final inverter cost is $\$ 385$, which is five times lower than the $\$ 1900$ from ORNL's cost study. The subcontractor has shown an ambitious path to reach this cost with advances in technology and product configuration as well as mass production. Note that the connectors and silicon cost is $46 \%$ of the total cost. An unanswered question for the $\$ 385$ inverter is, "What is the incremental cost impact of adding small volumes of silicon such as the DMIC's six anti-parallel diodes?" 
Table 5. Selection of expensive inverter components based on motor design voltages and simulation currents

\begin{tabular}{|c|c|c|c|c|c|}
\hline & Typical & Case 1 & Case 2 & Case 3 & Case 4 \\
\hline Part Name & Specifications & & & & \\
\hline IGBT Module & Dual $600 \mathrm{~V} / 600 \mathrm{~A}$ & Dual $800 V / 200 A$ & Dual 450V/450A & Dual 600V/200A & Dual 350V/450A \\
\hline DC Bus Capacitor & 5000uF/250VDC & 4000uF/660VDC & 5000uF/350VDC & 4000uF/500VDC & 5000uF/250VDC \\
\hline IGBT Snubber Capacitor & 9.0uF/600VDC & 6.0uF/900VDC & 9.0uF/600VDC & 6.0uF/600VDC & 9.0uF/600VDC \\
\hline DC Current Transformer & 400AT/4V DC,0-650AT DC & 200AT/4V DC & 400AT/4V DC,0-650AT DC & 200AT/4V DC & 400AT/4V DC,0-650AT DC \\
\hline SCR Module & Dual $2000 \mathrm{~V} / 430 \mathrm{~A}$ & \multirow{3}{*}{\multicolumn{2}{|c|}{ Not Applicable }} & Dual 2200V/80A & Dual 1100V/160A \\
\hline SCR Snubber Resistance & 10 ohm $2 \mathrm{~W}$ & & & & \\
\hline SCR Snubber Capacitor & $0.22 \mathrm{uF} 250 \mathrm{VAC}$ & & & $0.22 \mathrm{uF} 1550 \mathrm{VAC}$ & $0.22 \mathrm{uF} 800 \mathrm{VAC}$ \\
\hline
\end{tabular}

Table 6. Inverter costs for production volume of $\mathbf{1 0 , 0 0 0}$ units

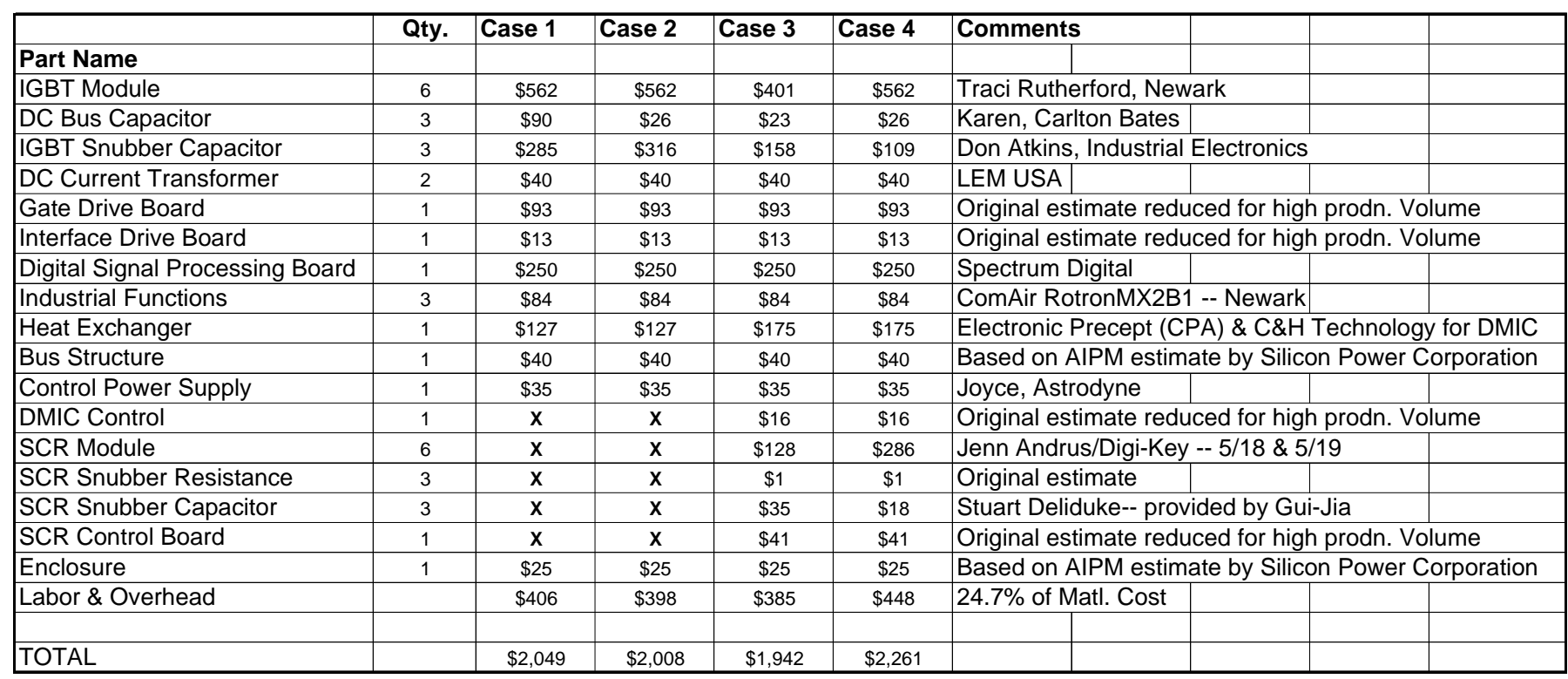




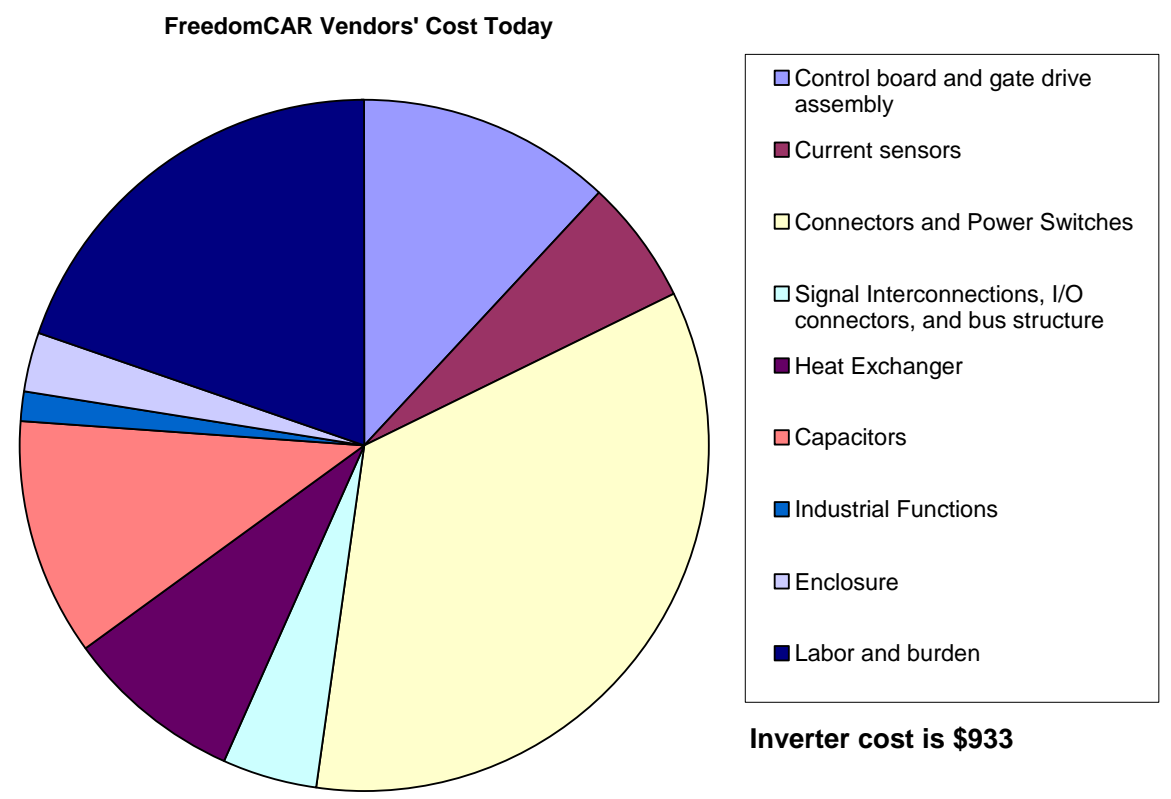

Fig. 7. Today's relative inverter component costs based on vendor estimates (100,000 units).
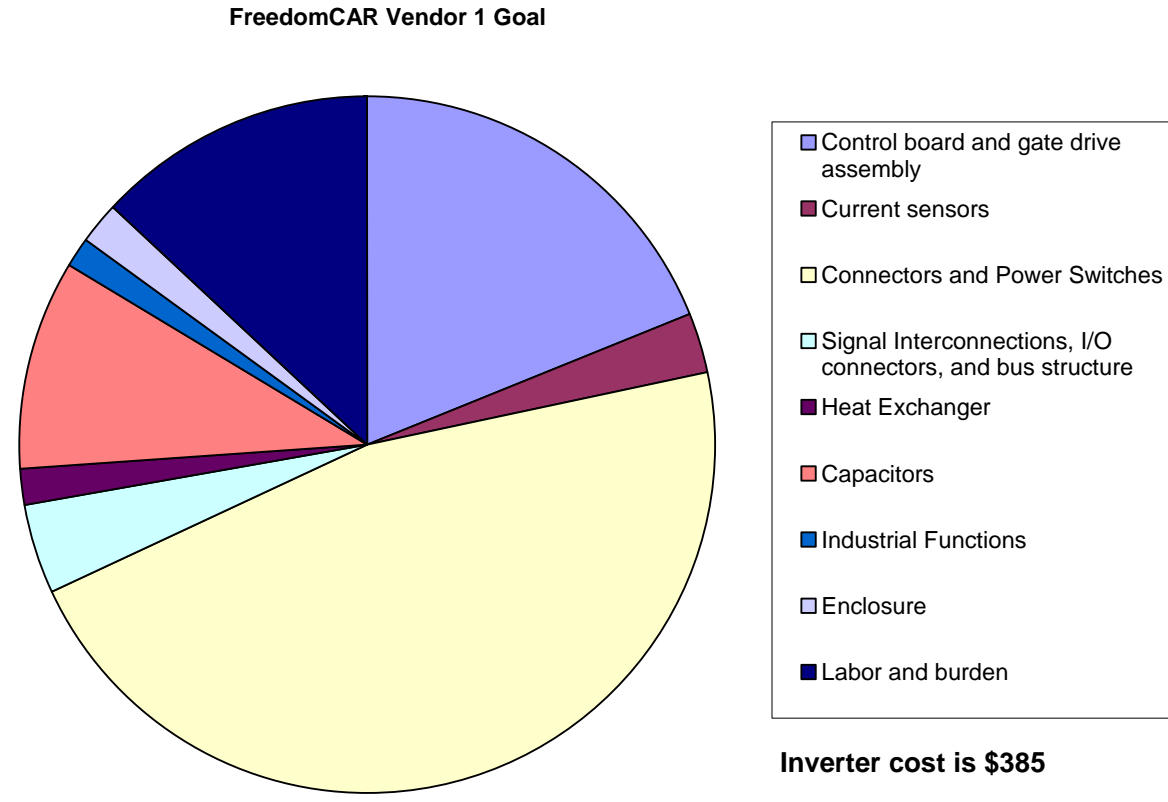

Labor and burden

Inverter cost is $\$ 385$

Fig. 8. Relative cost goal of inverter components for a FreedomCAR subcontractor. 


\subsection{ESTIMATING LIFE-CYCLE COSTS AND BENEFITS}

Intuitively, one might believe that since the DMIC involves six added semiconductors, specifically the SCRs, the DMIC is necessarily at a disadvantage relative to the first cost of CPA. Moreover, since the SCRs introduce an additional loss mechanism, it would appear that the DMIC would be at a further disadvantage relative to efficiency. Given this intuition, it is reasonable to ask whether there is any economic benefit to using the DMIC. In this section, we use the results of this study to show that the DMIC is not necessarily at a disadvantage relative to first cost. In other research ORNL is conducting a life-cycle cost benefit analysis with an industrial partner to explore benefits derived from using semiconductors with lower ratings and operating mainly in regions DMIC can reduce current to raise efficiency.

One conclusion of this study is that it is not difficult to design a PMSM having high internal inductance. This is true for the PMSM with sinusoidal back-emf as well as for the BDCM with trapezoidal back-emf. High-inductance machines do not require DMIC in order to operate over an extended CPSR; however, high-inductance machines do require a larger dc supply voltage to sustain rated power at the base speed condition, and the dc supply voltage affects the voltage rating of inverter components. Consider the high-inductance case 1 in Table 3 and the companion CPA inverter components of case 1 in Table 6 . The total first cost of this drive is $\$ 2290$. Alternatively, the lower-inductance case 3 in Table 3 and the companion DMIC inverter components of case 3 in Table 6 have a total first cost of $\$ 2292$; thus it is not necessarily true that there is a first cost penalty associated with the application of DMIC.

This study has also shown that the DMIC can reduce motor current magnitude during high-speed operation even for a high-inductance motor [11]. Observe in Fig. 4 that during high-speed operation, the rms motor current magnitude at any developed power level is lower for a high inductance PMSM using DMIC than for the same motor driven by CPA. Reduced-magnitude motor current reduces copper losses, which vary with the square of motor current, and reduces the losses in the inverter, which vary with the first power of motor current. Despite the additional loss mechanism introduced by the SCRs, there can be an overall reduction in total losses when using the DMIC. ORNL is conducting a study to compare the total energy in the losses of CPA and DMIC over the life of the drive. Total losses depend on speed and power level; consequently, an accurate model of the duty cycle of the drive is essential to performing the analysis. The model being developed includes motor copper losses as well as inverter loss mechanisms, including semiconductor conduction losses, switching losses, and reverse recovery losses. It is expected that the model developed will be sufficiently parametric to allow easy evaluation of the total energy losses over the drive lifetime for a variety of applications. 


\section{CONCLUSIONS}

Equations for maximum and minimum inductance limits have been derived for BDCMs with trapezoidal back-emfs driven with CPA and with DMIC. Similar equations for maximum and minimum inductance limits have been derived for PMSMs with sinusoidal back-emfs. The upper limit must not be exceeded; otherwise, the rated power may not be reached. Exceeding the lower limit allows the current to rise above the rated limit.

With the copper packing fraction adjusted to maintain constant current density, adjustment of the number of turns per slot and the motor length led to four designs, cases 1 through 4, for surfacemounted radial-gap PM motors. These motors covered the required range of inductances from 156 to $1270 \mathrm{uH}$ to compare CPA-controlled and DMIC drive system costs. Based on the equations for inductance limits, Cases 1 and 2 were for CPA control and cases 3 and 4 were for DMIC. The design code used was ORNL's radial gap design tool.

The OEM cost of the motor and inverter for four cases, based on communication with vendors and current material costs, was completed. It showed an average inverter cost of $\$ 2065$ and an average motor cost of $\$ 296$. The ratio of this study's inverter to motor cost ratio is 7:1. In a recent paper discussing cost optimization of interior PM synchronous machines [12] the ratio achieved was 8:1. These numbers are considerably higher than the 1.4:1 goal of FreedomCAR, which seems to confirm that efforts to reduce inverter costs have room for impact.

A counterintuitive result of the motor cost study was that reduced inductance added $\$ 111$ to the cost of cases 3 and 4 . To maintain power and torque, the reduction in the number of turns had to be accompanied by an increase in length, which is sensitive to material costs. Refinements can probably lower the cost of cases 3 and 4 slightly, which would raise the cost ratio above 7 .

The cost of the thyristor-associated components for the DMIC was $\$ 221$ for case 3 and $\$ 362$ for case 4. The difference in expense was caused by the large increase in current in case 4 because of case 4's lower back-emf, with corresponding lower voltage requirements and higher current requirements. Because of higher voltage and lower current, the added SCR costs for DMIC in the case 3 inverter were compensated by the reduced cost of the IGBTs. The result is that the case 3 DMIC drive system cost, $\$ 2292$, was only $\$ 2$ more than the case 1 CPA drive system cost. This suggests a potential to compensate for added SCR costs by carefully sizing the drive system, in this case to have increased voltage. It also attaches a penalty to higher-current systems.

An analysis using a phasor model of a PMSM has provided a relationship showing the current that may be saved at power levels up to rated power and relative speeds over 2 by using DMIC instead of CPA control. This information, along with the lifetime duty-cycle map of a given application, may be used to estimate life-cycle cost over the life of a vehicle, which may provide incentive for certain applications to employ DMIC.

ORNL and a commercial manufacturer are collaborating through a cooperative research and development agreement to examine both cost and performance justifications for using a traction drive that employs DMIC. The vendor's access to extensive cost information and experience in 
cost/benefit analysis both for initial cost and life-cycle cost will be focused on a specific application. 


\section{REFERENCES}

1. J. S. Lawler, J. M. Bailey, and J. W. McKeever, Extended Constant Power Speed Range of the Brushless DC Motor through Dual Mode Inverter Control, ORNL/TM-2000/130, UTBattelle, LLC, Oak Ridge National Laboratory, 2001.

2. J. S. Lawler and J. M. Bailey, Constant Power Speed Range Extension of Surface Mounted PM Motors, U.S. Patent Number 6,236,179 B1, May 22, 2001.

3. Cambier et al., Brushless DC Motor Using Phase Timing Advancement, U.S. Patent Number 5,677,605, October 14, 1997.

4. J. S. Lawler, J. M. Bailey, J. W. McKeever, and J. Pinto, "Limitations of the Conventional Phase Advance Method for Constant Power Operation of the Brushless DC Motor," Conference Proceedings of Southeast Conference on Power Electronics Applications, 2002.

5. J. S. Lawler, J. M. Bailey, and J. W. McKeever, "Theoretical Verification of the Infinite Constant Power Speed Range of the Brushless DC Motor Driven by Dual Mode Inverter Control," Proceedings of the 7th IEEE Workshop on Power Electronics in Transportation, Auburn Hills, Michigan, October 24-25, 2002.

6. J. S. Lawler, J. M. Bailey, J. W. McKeever, and J. Pinto, "Extending the Constant Power Speed Range of the Brushless DC Motor through Dual-Mode Inverter Control," IEEE Trans. on Power Electronics, 19, (3), May 2004.

7. J. Pinto, Analysis of Extended Constant Power Speed Range of the Permanent Magnet Synchronous Machine Driven by Dual Mode Inverter Control, Ph.D. Dissertation, the University of Tennessee, Knoxville, Tennessee, August 2001.

8. T. M. Jahns and V. Caliskan, "Uncontrolled Generator Operaion of Interior PM Synchronous Machines Following High-Speed Inverter Shutdown," pp. 1347-1357 in IEEE Trans. Industry Applications, 35, (6), November/December 1999.

9. J. W. McKeever, "Inverter Control for High CPSR, System Design, Safety, and Extra Power Delivery," DOE Office of FreedomCAR and Vehicle Technologies Program and ORNL Power Electronics and Electric Machinery Research Center Merit Review, June 5, 2003.

10. P. Pillay and R. Krishman, "Application Characteristics of Permanent Magnet Synchronous Motors and Brushless Dc Motors for Servo Drives," pp.380-390 in Proceedings of the 1987 IEEE Annual Meeting, Atlanta, Georgia, October 19-23, 1987.

11. J. S. Lawler, J. M. Bailey, and J. W. McKeever, "Minimum Current Magnitude Control of Surface PM Synchronous Machines during Constant Power Operation," submitted for publication in IEEE Power Electronics Letters, electronic journal, November 2004.

12. E. C. Lovelace, T. M. Jahns, and J. H. Lang, "Impact of Saturation and Inverter Cost on Interior PM Synchronous Machine Drive Optimization," pp.723-729 in IEEE Transactions of Inductry Applications, 36, (3), May/June 2000.

13. D. C. Hanselman, Brushless Permanent-Magnet Motor Design, McGraw-Hill, Inc., New York, ISBN 0-07-026025-7, 1994. 


\section{APPENDIX}

\section{SELF-INDUCTANCE AND ITS LIMITING PARAMETERS}

Inductance is the proportionality constant, $\mathrm{L}$, that relates the current flowing through a stator coil to the magnetic flux loops that link the coil according to the relation $\lambda=\mathrm{Li}$. The flux linkages may link only the coil itself, in which case it is called self-inductance; however, the flux linkages may link both it and another coil, in which case it is called mutual inductance.

If an electrical circuit's inductance is constant, the voltage across that inductance is related to the time rate of change of flux linkages by the relation $\mathrm{v}=-\mathrm{d} \lambda / \mathrm{dt}=-\mathrm{Ldi} / \mathrm{dt}$. This shows that the rate of change of current with time, $\mathrm{di} / \mathrm{dt}=-\mathrm{v} / \mathrm{L}$, can be reduced by increasing $\mathrm{L}$. From this relation, it follows that $\Delta \mathrm{I}=\mathrm{v} \Delta \mathrm{t} / \mathrm{L}$, which explains how a normal supply voltage, $\mathrm{v}$, can quickly produce undesirably high currents for small $\mathrm{L}$, as is the case with PM motors. One solution is to increase the value of $L$.

Stator inductance contains three components of inductance [13]. They are (1) the gap inductance, (2) the slot inductance, and (3) the end turn inductance. In a three-phase radial gap PM motor, the coil forms axially in slot one, moves into the end winding area, skips two slots, returns axially inward to slot four, and closes back into the first slot through the end winding on the opposite side. The flux loops that determine the self-inductance form a closed link around this coil.

For the gap inductance the flux loop that links the stator coil originates at and passes radially through the magnet, the gap, and the plane of the coil into the stator, where it divides into two equal oppositely directed circumferential paths. It then turns, flowing back radially through the gap and opposing magnet, passing circumferentially into the rotor back iron, and finally closing back on the original magnet. The expression for the gap inductance of one phase of a radial gap $\mathrm{PM}$ motor is

$$
\mathrm{L}_{\text {gap }}^{\text {PMM phase }}=\mathrm{N}_{\mathrm{s} / \mathrm{ph}} \frac{\mathrm{n}_{\mathrm{s}}^{2} \mu_{\mathrm{o}} \mu_{\mathrm{R}} \mathrm{L}_{\mathrm{st}} \tau_{\mathrm{c}}^{\mathrm{gap}} \mathrm{k}_{\mathrm{d}}}{4\left[\mathrm{l}_{\mathrm{m}}+\mu_{\mathrm{R}} \mathrm{k}_{\mathrm{c}} \mathrm{g}\right]},
$$

where

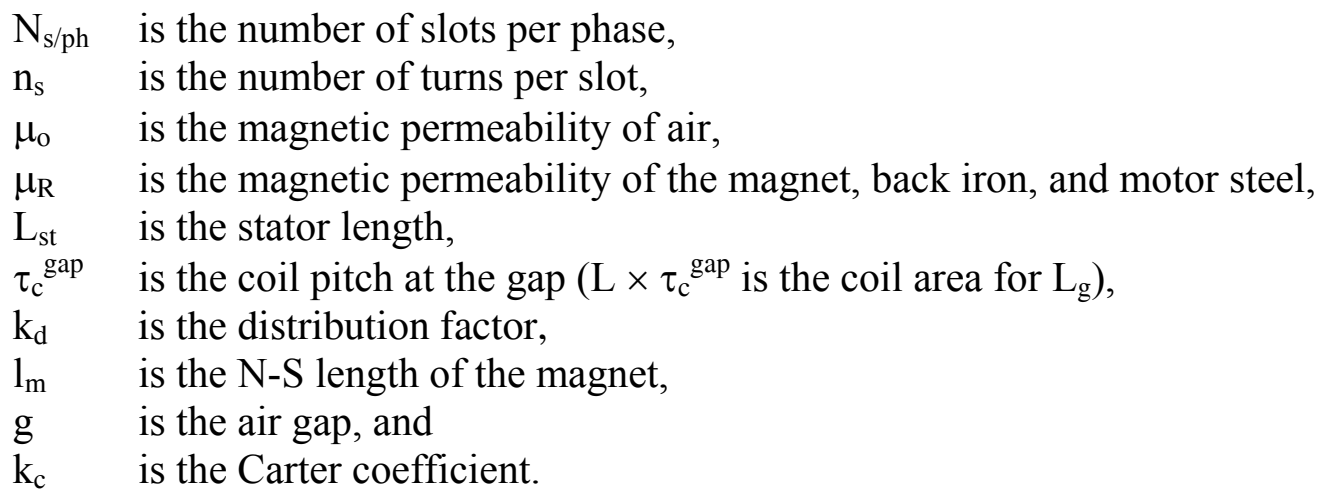


For the phase inductance, the flux loop that links the stator coil passes circumferentially across the slot into the stator, through which it closes the loop. At different radial positions in the slot, the flux loop encircles a different number of coil turns (flux links) so that the total inductance is the integral of the inductances over the slot depth. The expression for the slot inductance of one phase of a radial gap motor is

$$
\mathrm{L}_{\text {slot }}^{\text {PMMphase }}=\mathrm{N}_{\mathrm{s} / \mathrm{ph}} \mathrm{n}_{\mathrm{s}}^{2} \mu_{\mathrm{o}} \mathrm{L}_{\mathrm{st}}\left(\frac{\mathrm{d}_{3}^{2}}{3 \mathrm{~A}_{\mathrm{s}}}+\frac{\mathrm{d}_{2}}{\left(\mathrm{w}_{\mathrm{s}}+\mathrm{w}_{\mathrm{si}}\right) / 2}+\frac{\mathrm{d}_{1}}{\mathrm{w}_{\mathrm{s}}}\right),
$$

where

$\mathrm{d}_{3} \quad$ is the slot depth that contains coil wires,

$\mathrm{d}_{2} \quad$ is the radial distance from the top of the shoe to the top of the toe,

$\mathrm{d}_{1} \quad$ is the radial distance from the top of the toe to the sole of the shoe,

$\mathrm{A}_{\mathrm{s}}$ is the area in which the coil is wound,

$\mathrm{W}_{\mathrm{s}} \quad$ is the access slot width at the sole of the foot, and

$\mathrm{W}_{\mathrm{si}} \quad$ is the width of the slot at the top of the shoe.

The end turns are the two semicircular parts of each stator coil that connect the slot wires. For the end turn phase inductance, the flux loop that links the stator coil is estimated as if the end turns were straight pieces of wire whose current, ni, generates the field $H=n i /(2 \pi r)$. The integral used to obtain the inductance is from the wire radius to the radius of the semicircle. The expression for the inductance of the end turns in one phase of a radial gap motor is

$$
\mathrm{L}_{\mathrm{e}}=\frac{\mathrm{N}_{\mathrm{s} / \mathrm{ph}} \mathrm{n}_{\mathrm{s}}^{2} \mu_{\mathrm{o}} \tau_{\mathrm{c}}}{8} \ln \left|\frac{\tau_{\mathrm{c}}^{2} \pi}{4 \mathrm{~A}_{\mathrm{s}}}\right|
$$

where

$\tau_{\mathrm{c}} \quad$ is the coil pitch at the mean radius of the coil.

The total inductance for one phase of a radial gap PM motor is the sum of the three inductances. The greatest contributor to self-inductance is the slot inductance. For the set of motors used in the cost study described in this report, the largest inductance contributor was the slot inductance. The gap inductance was about half the slot inductance, and the end turn inductance was about 0.1 of the slot inductance. From the three equations for inductance, we see that all components of inductance are proportional to the square of the number of turns per slot, and that the two largest components are proportional to the length of the motor. These parameters cannot be varied indiscriminately because they must be consistent with the volume of the slots available for wire and the wire diameter. The software design code developed at ORNL, which uses the Hanselman equations [12], was exercised to define consistent motors for the cost study. 


\section{INTERNAL DISTRIBUTION}
1. D. J. Adams
2. J. M. Bailey
3. S. Das
4. E. C. Fox

5. J. S. Lawler

6. L. D. Marlino

7. J. W. McKeever

8-9. ORNL Laboratory Records

\section{EXTERNAL DISTRIBUTION}

10. S. A. Rogers, U.S. Department of Energy, EE-2G/Forrestal Building, 1000 Independence Avenue, S.W., Washington, D.C. 208585.

11. E. J. Wall, U.S. Department of Energy, EE-2G/Forrestal Building, 1000 Independence Avenue, S.W., Washington, D.C. 208585. 